\title{
Biomechanical properties of the biceps-labral complex submitted to mechanical stress ${ }^{1}$
}

\author{
Propriedades biomecânicas do complexo labrum-glenóide bicipital superior \\ submetido ao estresse mecânico
}

\author{
Adson do Socorro Sá Costa ${ }^{2}$, José Alberto Dias Leite ${ }^{3}$, Francisco Erivan Abreu Melo ${ }^{4}$, Sérgio Botelho Guimarães ${ }^{5}$ \\ 1. From the Department of Surgery, Post-graduation Program. Faculty of Medicine, Federal University of Ceará (UFC), Brazil. \\ 2. Orthopedic Surgeon, Post-Graduate Fellow (Master's Degree), UFC, Brazil. \\ 3. Associate Professor of Orthopedics and Traumatology. Department of Surgery, UFC, Brazil. \\ 4. Full Professor, Department of Physics, UFC, Brazil. \\ 5. Associate Professor of Surgery. Department of Surgery, UFC, Brazil.
}

\begin{abstract}
Purpose: To determine biomechanical properties of the superior labrum-biceps tendon complex submitted to continuous and sudden mechanical strain. Methods: Eighteen shoulder specimens from 15 unclaimed corpses, ages ranging from 20 to 40 years, were submitted to continuous or sudden tensile tests using 3 different traction machines. Shoulders presenting signs of degenerative diseases or preexisting traumatic lesions were excluded. Results: Rupture of the distal portion of the long hand of the biceps occurred when stretching forces reached $290 \mathrm{~N}$ in continuous traction and $384 \mathrm{~N}$ in sudden traction. No labral-complex lesions were observed. Conclusion: Either a simple continuous or a sudden uniaxial traction of the arm do not play a role in the genesis of superior labrum anterior-posterior (SLAP) lesions in the shoulder joint. produce
\end{abstract}

Key words: Biomechanics. Cadaver. Shoulder. Stress, Mechanical.

\section{RESUMO}

Objetivo: Determinar as propriedades biomecânicas do complexo labrum-glenóide bicipital superior submetido ao estresse mecânico contínuo ou repetitivo (repentino). Métodos: Dezoito ombros provenientes de 15 cadáveres não reclamados, idades na faixa de 20 a 40 anos, foram submetidos aos testes de tração contínua ou repentina usando três diferentes máquinas de tração. Foram excluídos do estudo os ombros que apresentavam lesões degenerativas ou evidências de lesões traumáticas pré-existentes. Resultados: Ocorreu ruptura da porção distal do tendão do bíceps sob a tensão contínua de 290 N e de 348N na tração repentina. Não foram observadas lesões no complexo labrum-bicipital. Conclusão: A simples tração contínua ou súbita do braço não produz lesões do complexo Labrum Glenóide Bicipital Superior (SLAP) na articulação do ombro.

Descritores: Biomecânica. Cadáver. Ombro. Estresse Mecânico.

\section{Introduction}

Superior labrum-biceps tendon complex lesions (SLAP) are traumatic lesions involving the superior labrum and the origin of the tendon of the long head of the biceps and are responsible for many cases of shoulder pain. In the overhead throwing athlete the pain may be disabling, especially as a long delay in arriving at the proper diagnosis and treatment is common. ${ }^{1}$ The lesion results from the tearing of the anterosuperior labrum from the glenoid due to the traction of the biceps tendon as the elbow is decelerated during the follow-through phase of throwing. ${ }^{1}$ Snyder et al. ${ }^{2}$ coined the acronym SLAP to represent lesions of the superior labrum from anterior to posterior. According to Andrews et al. ${ }^{1}$ these lesions are the consequence of combined compression forces acting on the superior joint surface and the proximal forces with associated subluxation of humeral head resulting in trapping of the labrum and the long hand of the biceps between the humeral head and the glenoid following a fall on the outstretched hand. Clavert et al. ${ }^{3}$ studied the effects on the superior labrum-biceps tendon complex of a fall on the outstretched hand in a cadaver model and found lesions similar to those induced by a servohydraulic testing machine (INSTRON 8500+). Burkhart et al. ${ }^{4}$ state that type 2 SLAP lesions that cause the dead arm syndrome in overhead-throwing athletes are most likely acceleration injuries that occur in late cocking rather than deceleration injuries in follow-through. The peel-back mechanism (external rotation of humeral head around the biceps tendon) is a likely cause of posterior type 2 SLAP lesions.

This paper was aimed at determining the biomechanical properties of the superior labrum-biceps tendon complex submitted to continuous and sudden mechanical stress 
considering that controversies concerning the mechanisms of the SLAP lesions still exist.

\section{Methods}

Approval for the study was obtained from the Commission of Ethics in Research, Federal University of Ceará. Eighteen healthy shoulders from fifteen fresh-frozen unclaimed cadavers were utilized. The dissection was carried out after overnight thawing at room temperature. Specimen samples presenting traumatic or degenerative illnesses were excluded. The mean age of the donors, all men, ranged from 20 to 40 years.

\section{Specimen preparation}

After harvesting the shoulder specimens, two different specimen samples were prepared. Following removing all soft tissue, the humerus and scapula were preserved articulated, along with the long head of the biceps tendon (specimen sample type A). Specimen type B consisted of the retained glenohumeral capsule, the labrum and the entire length of the long head of the biceps tendon.

\section{Mechanical assays}

Three different devices were used for mechanical assays: 1- Dynamical strain machine with automatic selfacquiring data device (MTD); 2- Uniaxial strain machine (MTUE) developed at the Physics Laboratory of the UFC ${ }^{5}$; 3 - Dynamical strain electromechanical test instrument (Instron 4443). Video-arthroscopy equipment was used to obtain images of the procedure. The first experiment (dynamic traction test) was carried out using the MTD machine. Each specimen was mounted in the testing apparatus. The scapula was fixed by four stainless steel screws to a custom-designed metal holder and the terminal segment of the long head of the biceps was maintained in place with a metal clamp. For the second experiment, the setup was similar to the described above. The strain was obtained using the same machine (MTD) inducing a sudden strain to the tested specimen sample (Figure 1). In the third experiment (static strain test) the glenoid was fastened with stainless steel wires and involved with bone cement (polymethylmetacrylate) and the tendon was held in place by means of a metal clamp (Figures 2 and 3). Three specimens were submitted to the test, utilizing the MTUE testing machine. Maximum force produced by this device is $5200 \mathrm{~N}$ ( $\mathrm{s}=340 \mathrm{MPa}$ ). Tendon length was measured with a pachymeter.and the biceps tendon width (transverse section) was calculated with an ultrasound echo scan device. Tests were repeated five times for each specimen.

Continuous strain test was applied to three specimen samples; the glenoid and the tendon were fastened to the vertical mechanical holder. The tests were performed in the Instron 4443 testing machine. Maximum force applied was $1000 \mathrm{~N}$ (Figure 4).

Before testing, each specimen underwent an arthroscopic examination to exclude specimens with any preexisting injury to the labrum, biceps tendon, or glenohumeral ligaments. The glenohumeral normal anatomy and its variations were carefully evaluated and the findings were written down. The results were analyzed using the least-square method of linear regression in order to obtain the constants of the material and the dimensions of specimen samples.

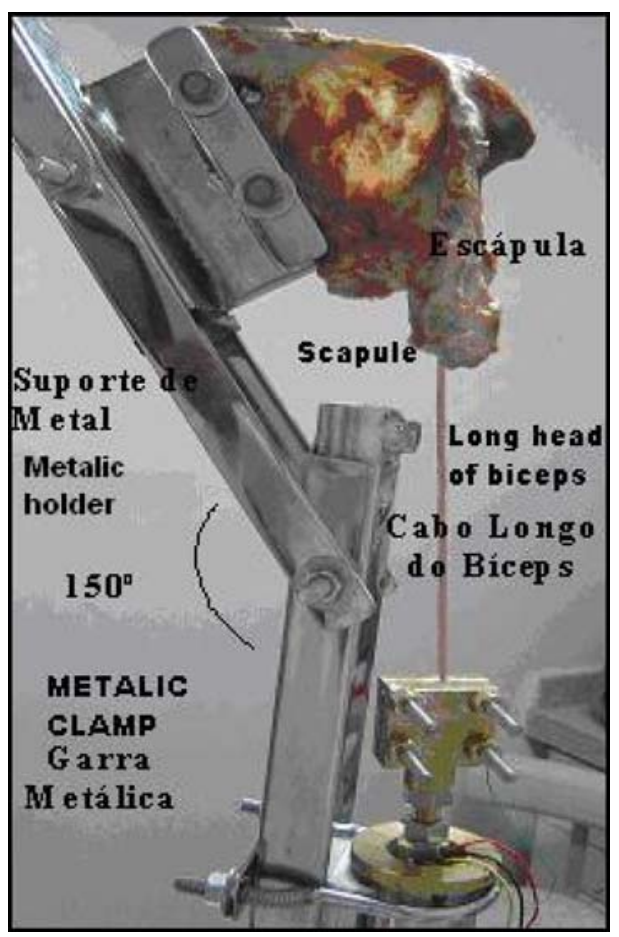

FIGURE 1 - Detail of specimen sample type A fastened to the MTD machine

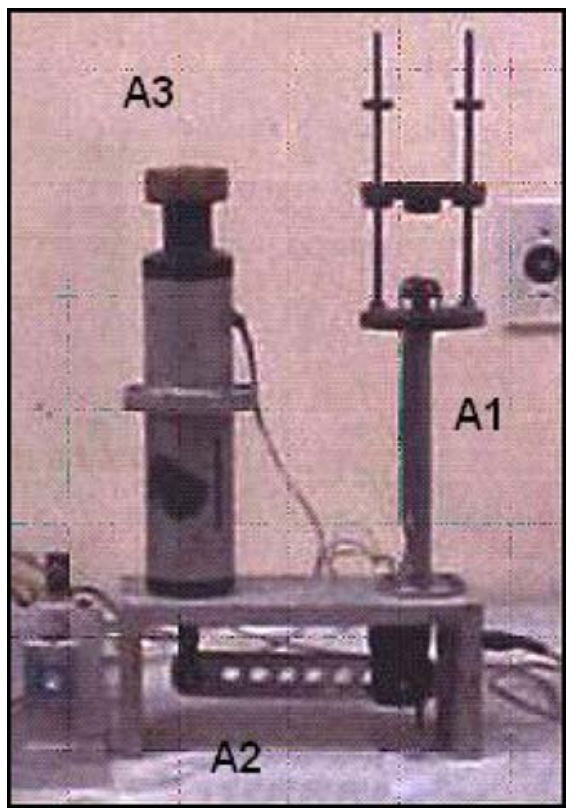

FIGURE 2 - Font view of the testing apparatus (MTUE), identifying the main parts: A1 - specimen holder; A2: winch; A3: handspike 


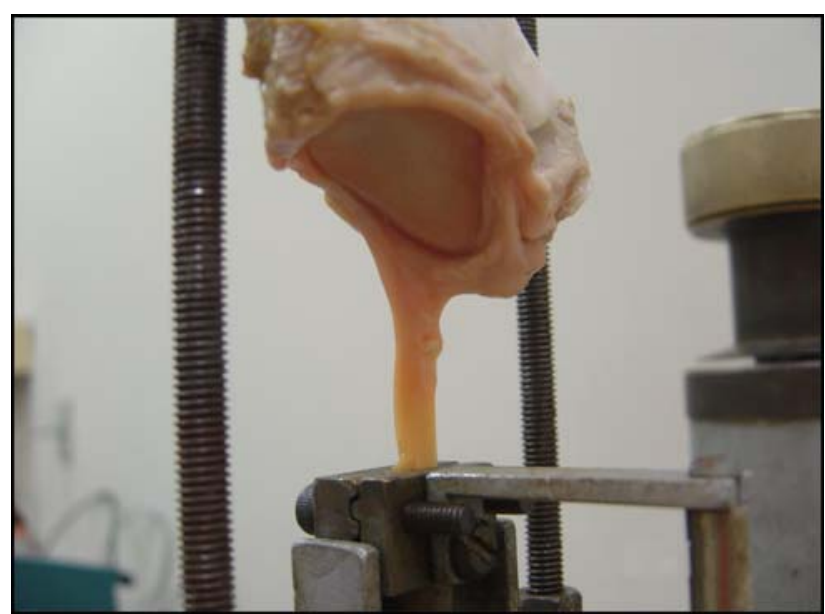

FIGURE 3 - Testing setup. Specimen sample type B fastened to the MTUE machine

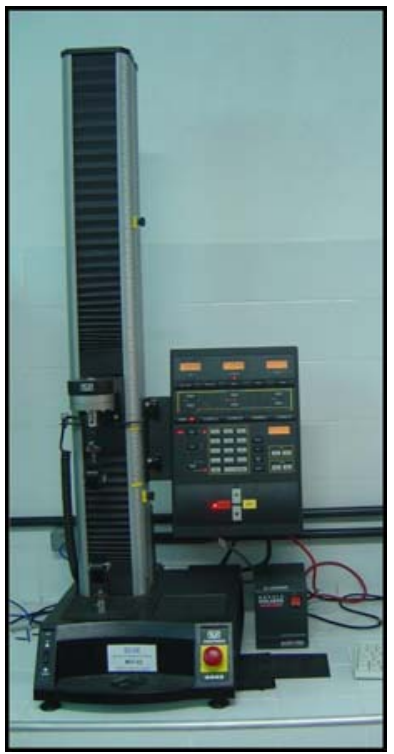

FIGURE 4 - Front view of the dynamical strain electromechanical test instrument (Instron 4443)

\section{Results}

Figures 5 to 7 depict curves obtained when a force was applied to the specimen samples type A. Figure 8 shows the curve obtained when a sudden strain was applied to the specimen samples type A.

Figure 5 displays the values obtained during the continuous traction test in MTD (applied force versus time) in specimen sample A. Force was applied $13000 \mathrm{~ms}$ after the MTD was linked to the Data Acquisition System. The graph shows clearly the three phases of deformation of the specimen samples A submitted to uniaxial traction: Accommodation Phase of (between 13.000-15.000 ms), Elastic Phase (between 15.000-30.000 ms) and Plastic Phase (above $30.000 \mathrm{~ms}$ ). The force applied to the specimen samples (Force $\mathrm{x}$ Time) reached $200 \mathrm{~N}$ in the Elastic Phase. In the graph depicted (Figure 6), the rising segment of the curve corresponds to the load, and the descending segment corresponds to the discharge (unload). Ruptures were not observed in the specimen samples A.

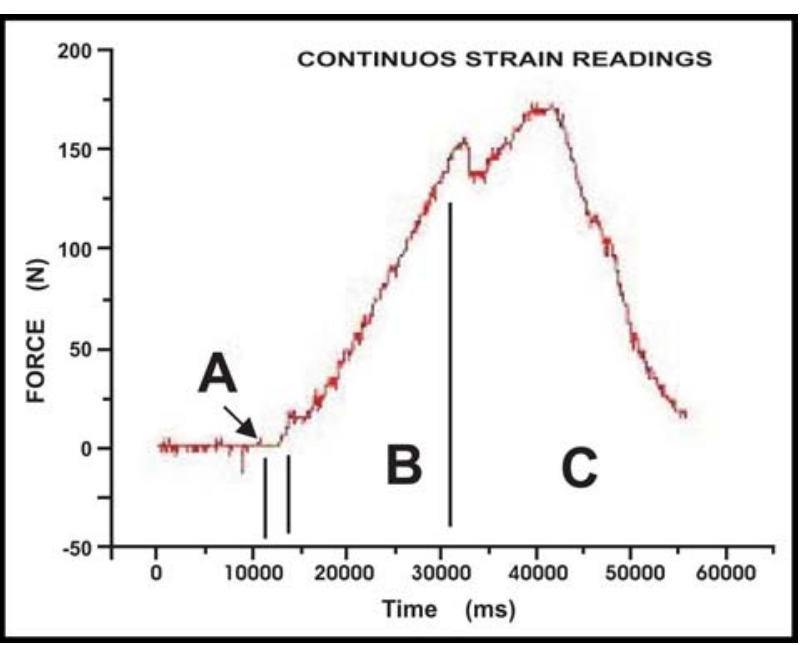

FIGURE 5 - Curve obtained (applied force in time) during continuous strain test using the MTD testing device. Legends: [A]: accommodation phase [B]: elastic phase [C]: Plastic phase

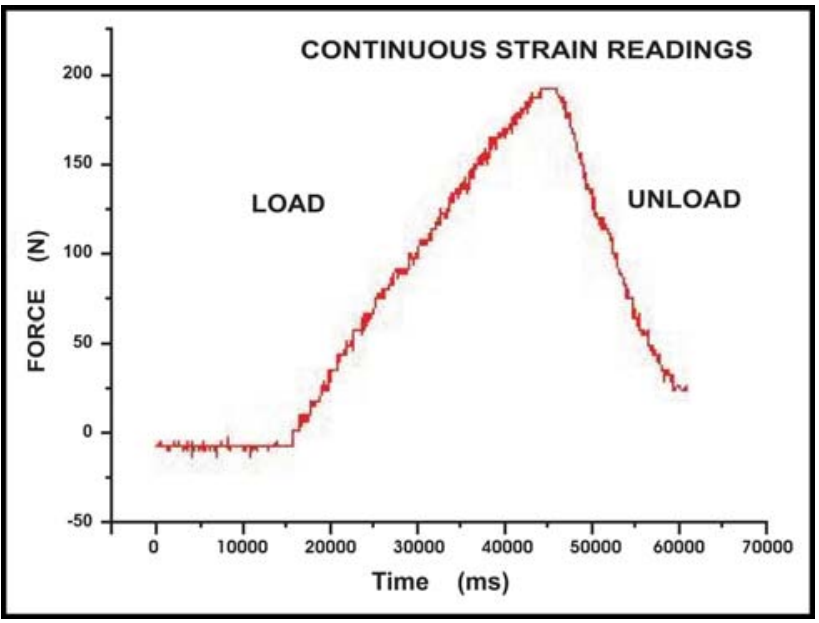

FIGURE 6 - Curve obtained when a continuous force was applied to the specimen sample A - Elastic phase (Force x Time)

With the application of the traction force to the specimen sample A $(290 \mathrm{~N} / 33.000 \mathrm{~ms})$ an abrupt fall of the force intensity was observed, indicating the rupture of the specimen sample. The rupture happened at the point where the biceps tendon was fastened to the MTD machine. Arthroscopic examination did not elicit any biceps-labral complex lesions (Figure 7)

During the experiments accomplished in MTD machine (sudden traction), the machine's spring was totally extended, but without applying any force to the tested specimen samples. This was possible with the aid of metallic chucks that arrested the metallic clamps attached to one of the extremities of the tendon. Sudden traction was applied to the specimen samples by abrupt removal of the chucks, 
leaving the metallic clamps free in synchronism with the spring movements within the MTD machine (Figure 8).

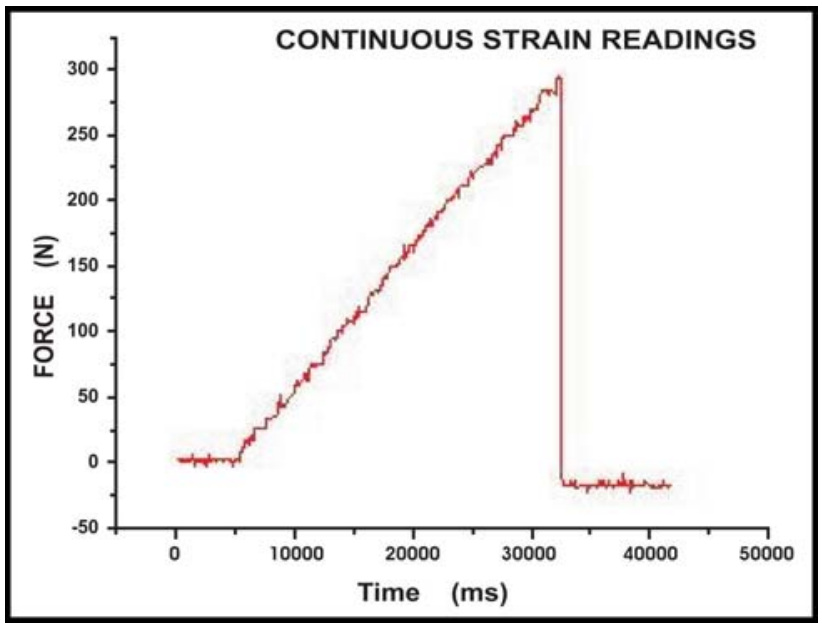

FIGURE 7 - Rupture of specimen sample A under continuous strain. Rupture occurred at $290 \mathrm{~N}$

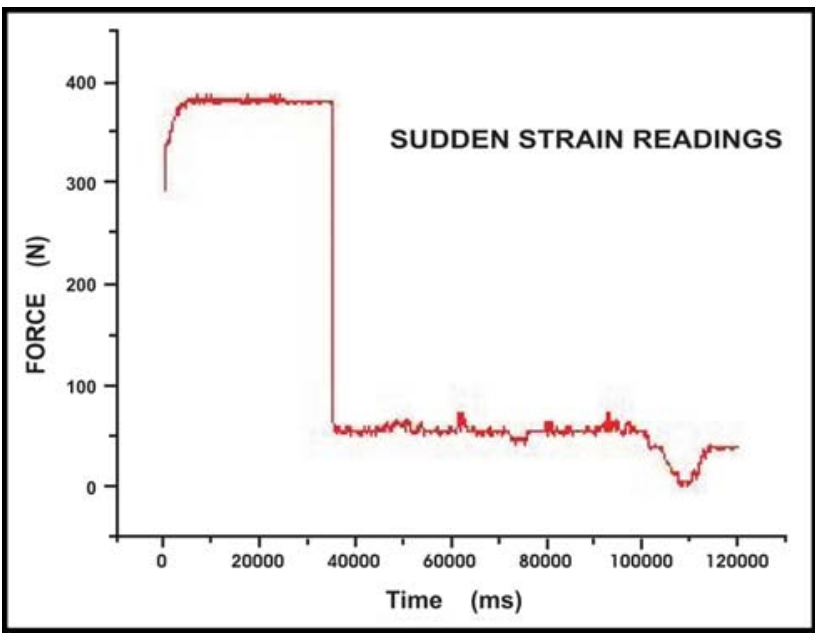

FIGURE 8 - Graph (Force x Time) depicting the rupture (vertical straight line) of specimen sample A (sudden strain test)

Figure 8 illustrates the force applied to the metallic chucks $(384 \mathrm{~N})$. When a sudden traction is applied (abrupt removal of metallic chucks), the force (384N) used in the experiment is transmitted to the tendon. This effect is identified in the graph by the vertical straight line for a time of $35.000 \mathrm{~ms}$. The time of transmission of the impact was $210 \mathrm{~ms}$. The Force of Impact was 321N ( F1 - F2 = 384N - 63N $=321 \mathrm{~N}$ ). It is possible to calculate the value of $\mathrm{J}$ (Impulse) using the equation $Y=\frac{\sigma}{\varepsilon}=\frac{F l_{0}}{S \Delta l}$ as demonstrated:

$\mathrm{J}=\int_{0}^{0,21} F(t) d t=\bar{F} \Delta t=231 \times 0,21 \mathrm{~N} . \mathrm{s} \rightarrow \mathrm{J}=48,51 \mathrm{~N} . \mathrm{s}$
Specimen samples $B$ assay using the static uniaxial traction machine (MTUE):

Maximum force supported by the specimen sample B was $275 \mathrm{~N}$ and minimum force was $62 \mathrm{~N}$. Lesions were not observed in the compound labrum-bicipital through the ocular vision. The ruptures were observed at the point where the distal portion of the tendon was fastened close to the metallic clamps of the MTUE machine. These lesions were similar to those observed when using the MTD testing machine.

Specimen samples B assay using the Dynamic traction machine INSTRON 4443

Force tolerance limits for specimen samples type B ranged from $158,1 \mathrm{~N}$ to $340,9 \mathrm{~N}$. No lesions of biceps-labral complex occurred in this assay. Ruptures occurred at the distal tendon segments close to the metal clamps, in similar manner to those observed in the MTD machine assay.

\section{Discussion}

Andrews et al. ${ }^{1}$ hypothesized that the SLAP lesion resulted from the traction imposed to the biceps tendon during repeated throw movements. The same type of lesions were reproduced in Burkhart et al. ${ }^{4}$ and Kuhn et al. ${ }^{6}$ experiments.

Vaitl et al. ${ }^{7}$ found SLAP lesions in $83 \%$ of the shoulders submitted to the tests, during the deceleration phase of the throw. Snyder et al. ${ }^{2}$ claim that the fall with the extended arm, producing a compression force with a proximal subluxation, is the major mechanism of the SLAP lesion. Calvert et al. ${ }^{3}$ experiments substantiated Vaitl et al. ${ }^{7}$ hypothesis. Maffet et al. ${ }^{8}$ claimed that the lesion could be the result of a sudden traction on the arm, as happens to occur when some lifts a heavy object. There are no literature evidences to support this hypothesis.

The exam of the specimen samples subjected to the uniaxial load showed that when the applied tension doesn't surpass the limit of the elasticity of the material, there is a return to the initial conditions as soon as the load is removed. On the other hand, a load can be repeated many times, providing that the applied tensions stay inside of values of the elastic regime. This condition stops being valid when the number of load repetitions exceeds thousands of times (repetitive traction).

The rupture of the specimen samples occurred well below the rupture tension obtained with the static load was applied. In that case, the rupture of specimen sample happened for fatigue. The rupture for fatigue is always a fragile rupture, even for materials of great resistance. It was observed that all lesions, whether induced by continuous or sudden uniaxial traction, occurred in the distal portion of the biceps tendon. It was not possible to reproduce the SLAP lesion in the experiments accomplished by applying continuous or sudden tractions using the uniaxial strain machines. Future studies, using the robotics, the cinematography, the computation, and with the aid of the arthroscopy, may help to validate whether the compound 
labrum bicipital superior lesions are generated by a traction force or by compression in the long head of the biceps, a flaw of the dynamic action of the biceps in the position of extreme rotation of the shoulder, the position assumed by the arm when the trauma happens, the existence of anatomical variants or local degenerative processes, or still, for the sum of all these factors.

\section{Conclusion}

Either a simple continuous or a sudden uniaxial traction of the arm are not capable of generating superior labrum anterior-posterior (SLAP) lesions in the shoulder joint.

\section{References}

1. Andrews JR, Carson WG, Mcleod WD. Glenoide labrum tears related to the long head of the biceps. Am J Sports Med. 1985;13:337-41.

2. Snyder SJ, Karzel RP, Del Pizzo W. SLAP lesions of the shoulder. Arthroscopy. 1990;6:274-9.
3. Clavert P, Bonnomet F, Kempf FJ, Boutemy P, Braun M, Kohn LJ. Contribution to the study of the pathogenesis of type II superior labrum anterior-posterior lesions: a cadaveric model of a fall on the outstretched hand. $\mathrm{J}$ Bone Joint Surg. 2004;13:45-50.

4. Burkhart SS, Morgan CD, Kibler WB. Shoulder injuries in overhead athletes: the "dead arm" revisited. Clin Sports Med. 2000;19:125-58.

5. Melo FE. Transições de fase e efeitos anarmônicos das vibrações da rede: Lilo3 [Tese]. Campinas: Universidade de Campinas (UNICAMP); 1983.

6. Kuhn JE, Stephen RL, Houston JL, Soslowsky JL, Blasier RB. Failure of the Biceps Superior Labral Complex: a cadaveric biomechanical investigation comparing the late cocking and eairly deceleration positions of trowing. Arthroscopy. 2003;19(4):373-9.

7. Vaitl T, Burkart A, Steinhauser E, Hohmann E, Imhoff A. Pathogenese der SLAP-II-Läsion am Schultergelenk. Orthopäde. 2003;32:608-15.

8. Maffet WM, Gartsman GM, Moseley B. Superior labrumbiceps tendon complex lesions of the sholder. Am J Sport Med. 1995;23:93-8.

\section{Correspondence:}

Dr. José Alberto Dias Leite

Department of Surgery

Rua Prof. Costa Mendes, $1608 / 3^{\circ}$ andar

60430-140 Fortaleza-CE Brazil

Phone: (55 85)4009-8063

Fax:(5585)4009-8064

mcirur@.ufc.br
Conflict of interest: none

Financial source: none

Received: January 05, 2006

Review: February 12, 2006

Accepted: March 20, 2006

\section{How to cite this article:}

CostaASS, Leite JAD, Melo FEA, Guimarães SB. Biomechanical properties of the biceps-labral complex submitted to mechanical stress. Acta Cir Bras. [serial on the Internet] 2006 July-Aug;21(4). Available from URL: http://www.scielo.br/acb 